\title{
DIGITAL MARKETING PADA UKM : IDENTIFIKASI RISET GAP MELALUI STUDI LITERATUR REVIEW
}

\author{
Rihan Hafizni ${ }^{1)}$, Rahmi Fahmy ${ }^{2)}$ \\ ${ }^{1}$ Program Doktor Ilmu Manajemen, Universitas Andalas \\ ${ }^{2}$ Fakultas Ekonomi Manajemen, Universitas Andalas \\ email: rhafizni76@gmail.com
}

\begin{abstract}
Abstrak
Abstrak : Perkembangan digitalisasi semakin cepat, seiring dengan pertumbuhan penggunaan internet. Data dari Kominfo pengguna internet di Indonesia tumbuh 10,2 persen setiap tahunnya atau sekitar 27 juta pengguna, jika dibandingkan dengan pengguna internet di dunia, Indonesia menempati peringkat ke-5. Kondisi ini membuat perubahan yang sangat drastis bagi dunia marketing, yaitu perubahan sistem dari konvensional kepada digital. Kebutuhan untuk melakukan penelitian tentang penggunaan digital marketing di UKM merupakan hal yang sangat penting. Tujuan dari penelitian ini untuk mengembangkan pemahaman tentang penelitian yang terkait dengan pemasaran digital pada UKM, dan menemukan riset gap pada penelitian yang diterbitkan antara tahun 2015 hingga tahun 2020. Untuk menganalisis dan mengkaji literatur yang bertemakan digital marketing di UKM, menggunakan analisis sistematis dan mengklasifikasikan data yang dipublikasikan dari jurnal pemasaran, jurnal ekonomi, bisnis dan manajemen serta jurnal IT yang dapat diakses secara online. Hasilnya menunjukkan. terdapat kesenjangan penelitian dibidang digital marketing, untuk mengisinya, perlu dilakukan penelitian untuk menyelidiki peluang yang diciptakan oleh digital marketing untuk UKM di Indonesia.
\end{abstract}

Kata kunci: Digital marketing, UKM, Riset gap

Abstract: The development of digitalization is getting faster, along with the growth in internet usage. Data from Kominfo, internet users in Indonesia, grow 10.2 percent annually or around 27 million users, when compared to internet users in the world, Indonesia is ranked 5th. This condition makes a very drastic change in the marketing world, namely a system change from conventional to digital. The need to conduct research on the use of digital marketing in SMEs is very important. The purpose of this study is to develop an understanding of research related to digital marketing in SMEs, and find research gaps in research published between 2015 and 2020. To analyze and reviewing literature on the theme of digital marketing in SMEs, using systematic analysis and classifying published data from marketing journals, economics, business and management journals as well as IT journals that can be accessed online. The results show. There is a research gap in the field of digital marketing, to fill it, research is needed to investigate the opportunities created by digital marketing for SMEs in Indonesia.

Keywords: Digital marketing, SMEs, Research gap

\section{PENDAHULUAN}

Perkembangan digitalisasi semakin cepat, seiring dengan pertumbuhan penggunaan internet. Berdasarkan data dari Kominfo pengguna internet di Indonesia tumbuh 10,2 persen setiap tahunnya atau sekitar 27 juta, dan jumlah pengguna internet di Indonesia-mencapai 171 juta hingga bulan Mei 2019. Kondisi ini membuat perubahan yang sangat drastis bagi dunia marketing, dimana terjadi perubahan sistem dari konvensional kepada digital sistem. Perubahan sistem digitalisasi ini meliputi penggunaan AI, seperti: e-commerce, platform web, social media, dan email (M Haenlein, 2019).

Digital marketing merupakan sistem pemasaran yang terintegrasi, interaktif, dan terpadu, untuk memudahkan interaksi antara produsen, perantara, dan konsumen 
(L Bollweg, 2020). Digital marketing memberikan kemudahan bagi pelaku bisnis untuk memantau dan menyediakan kebutuhan dan keinginan konsumen (YS Chen, 2017). Sedangkan konsumen, lebih mudah mencari dan mendapatkan informasi produk dengan cara menjelajahi dunia maya (SM Chege, 2020).

Konsumen saat ini semakin mandiri dalam membuat keputusan pembelian berdasarkan hasil searching. Digital marketing dapat menjangkau seluruh konsumen dimanapun mereka berada tanpa ada lagi batasan geografis ataupun sekat ruang dan waktu.

Namun, tidak semua perusahaan ataupun industri mampu beradaptasi dengan mudah terhadap sistem digital ini terutama bagi perusahaan skala menengah dan skala kecil. Banyak kendala yang mereka hadapi, menyangkut sumber daya dan keterbatasan pengetahuan teknologi. UKM harus menghadapi perubahan ini agar mampu bersaing untuk meningkatkan kinerja perusahaan secara keseluruhan $(\mathrm{H}$ Bouwman, 2019).

Oleh karena itu pada makalah ini penulis tertarik untuk mengkaji lebih jauh dan menganalisis literatur review yang berkaitan dengan penggunaan digital marketing pada UKM. Penulis menggunakan analisis sistematis dan mengklasifikasikan data yang dipublikasikan dari jurnal pemasaran, jurnal bisnis dan manajemen serta jurnal IT yang dapat diakses secara online. Adapun tujuan penelitian ini agar dapat memberikan kontribusi bagi UKM dalam menghadapi transformasi digital marketing dan untuk mengembangkan pemahaman yang jelas tentang penelitian yang terkait dengan pemasaran digital bagi UKM, selain itu untuk mengeksplorasi secara empiris semua poin penelitian yang berbeda terkait dengan studi digital marketing yang diterbitkan antara tahun 2015 hingga tahun 2020.

\section{Digital Marketing}

Digital marketing merupakan penggunaan teknologi dalam upaya pemasaran produk, jasa, ide, praktik bisnis, brand value dan memastikan pertumbuhan dan visibilitas yang lebih baik (P Foroudi, 2017).

Pemasaran yang didorong data mengungkap berbagai strategi untuk mendekati, menarik, menyadarkan, menyenangkan, dan mengarahkan pelanggan ke pemasaran online. Pemasaran digital menurut (C Chung, 2012) mendefinisikannya sebagai : "Penggunaan data dan aplikasi elektronik untuk perencanaan dan pelaksanaan konsepsi, distribusi dan ide, barang dan jasa untuk menciptakan pertukaran yang memuaskan baik bagi individu maupun organisasi. Sementara (S Molinillo, 2017) mendefinisikannya sebagai : "Mencapai tujuan pemasaran melalui penerapan teknologi digital".

\section{Usaha Kecil Menengah (UKM)}

UKM merupakan jenis usaha yang dijalankan dengan skala kecil dan menengah dan bukan anak perusahaan atau cabang perusahaan mana pun. (K. U. Mikro) Menurut Undang-undang Nomor 9 tahun 1995, yang dimaksud dengan usaha kecil adalah: usaha produktif yang berskala kecil dan memenuhi kriteria kekayaan bersih paling banyak Rp.200.000.000,00 (dua ratus juta rupiah) tidak termasuk tanah dan bangunan tempat usaha atau memiliki hasil penjualan paling banyak Rp.1.000.000.000,00 (satu milyar rupiah) per tahun serta dapat menerima kredit dari bank maksimal di atas Rp.50.000.000,00 (lima puluh juta rupiah) sampai Rp.500.000.000,00 (lima ratus juta rupiah).

UKM diharapkan dapat mengadopsi teknologi digital marketing untuk meningkatkan kinerja perusahaan (R Yadav, 2019). Penelitian ini mempelajari penelitian masa lalu yang dilakukan oleh para peneliti dari 5 tahun terakhir. Tujuan penelitian ini untuk melihat riset gap pada 
penelitian terdahulu. Artikel yang telah terkumpul meyakini bahwa pemasaran digital masih perlu dianalisis sehingga mendapatkan pengetahuan yang lebih luas.

\section{METODE PENELITIAN}

Dalam pengumpulan literatur, penulis menggunakan software Publish Or Perish (POP). Pada kolom keyword dituliskan digital marketing, SMEs serta tahun penerbitan dibatasi antara tahun 2015 hingga tahun 2020, pencarian dilakukan melalui Scoopus sebagai basis data. Ada 3 tahapan yang dilakukan pada proses pemilihan artikel. Selanjutnya software akan bekerja mencari semua artikel yang berhubungan dengan keyword. Dari 200 artikel yang ditampilkan penulis melakukan tahapan pertama dan terpilih 50 artikel yang memiliki kesuaian tema. Selanjutnya penulis melakukan tahapan kedua dengan menyeleksi artikel lebih dalam, terpilih menjadi 15 artikel.

Pada tahapan yang ketiga dilakukan pemetaan artikel menggunakan Excel dan Vosviewer, file data disimpan dalam bentuk ris, agar dapat terbaca oleh Vosviewer selanjutnya software akan memetakan berdasarkan keyword, sehingga memudahkan untuk melihat area mana yang masih belum banyak dikaji peneliti terdahulu.seperti tampak pada gambar 1 yang merupakan tahapan seleksi artikel.

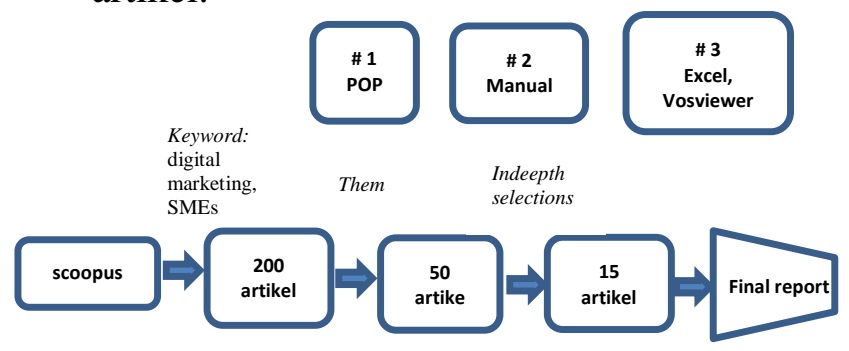

Gambar 1.Tahapan Seleksi Artikel

\section{HASIL DAN PEMBAHASAN}

Makalah ini memiliki latar belakang pengetahuan yang masih terbatas, menyajikan tinjauan literatur singkat tentang digital marketing dan UKM dari tahun 2015 hingga 2020 untuk mengeksplorasi bagaimana pemasaran dan aplikasi digital yang telah diteliti dalam periode ini.

\section{Desain Penelitian}

Berdasarkan 15 artikel yang telah terpilih menunjukkan bahwa $40 \%$ atau 6 artikel menggunakan desain penelitian metode survei, $20 \%$ atau 3 artikel menggunakan studi literatur, $7 \%$ atau 1 artikel menggunakan desain penelitian studi eksperimental, 13\% atau 2 artikel menggunakan studi Eksplorasi, $13 \%$ studi kasus dan 7\% artikel menggunakan desain penelitian strategi konseptual. Hal ini menunjukkan bahwa desain penelitian dengan metode survei lebih banyak digunakan, seperti tampak pada gambar 2 berikut ini.

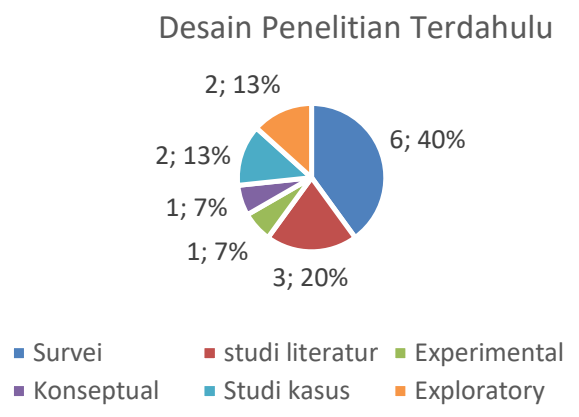

Gambar 2. Desain Penelitian

\section{Metodologi}

Jika dilihat dari metodologi yang digunakan, maka dari 15 artikel yang menggunakan metode kualitatif sebanyak 34\%, kuantitatif 53\% dan mix methode sebanyak $13 \%$. Hal ini menunjukan penelitian kuantitatif lebih banyak diminati untuk melihat pengaruh, konfirmasi, dan hubungan antar variabel yang diteliti. Seperti tampak pada gambar 3 berikut ini. 


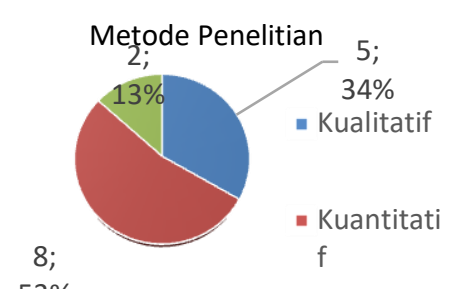

Gambar 3. Metode penelitian

\section{Analisis Topik}

UKM membutuhkan bimbingan yang tepat dalam membuat pilihan teknologi yang sesuai dengan kebutuhan mereka. Setelah diamati 53\% artikel membahas tentang transformasi dan adopsi teknologi digital sedangkan $40 \%$ artikel membahas tentang sosial media dan digital platform sedangkan yang lainnya sebanyak $7 \%$ membahas tentang bisnis model inovasi. Seperti tampak pada gambar 4 berikut ini.

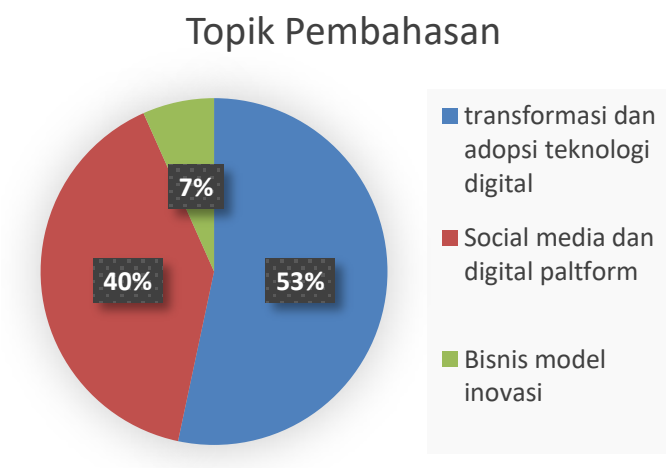

Gambar 4. Topik Pembahasan Artikel

Hal ini dapat mewakili kurangnya penelitian yang mencerminkan gambaran yang jelas tentang pemasaran digital, e-commerce, dan pemasaran internet.

\section{Taksonomi Penelitian: 2015-2020}

Pada Tabel 1 menggambarkan sebaran artikel yang dimuat dalam database jurnal terkait dengan literatur topik penelitian yaitu digital marketing dan UKM dari tahun 2015 hingga 2020.
Tabel 1. Sebaran Artikel digital marketing dan UKM tahun 2015-2020

\begin{tabular}{|l|l|}
\hline \multicolumn{1}{|c|}{ Nama Jurnal } & \multicolumn{1}{|c|}{ Tahun } \\
\hline $\begin{array}{l}\text { Journal of } \\
\text { Telecommunications } \\
\text { Policy }\end{array}$ & 2017 \\
Journal of Business & \\
Research & 2018,2020 \\
International Journal of \\
Information Management & 2016, \\
Asia-Pacific Journal of \\
Business Administration \\
$\begin{array}{l}\text { Journal of Management } \\
\text { Science Letters }\end{array}$ & 2017 \\
Information Technology \\
for Development \\
$\begin{array}{l}\text { Journal of Small Business } \\
\text { and Enterprise } \\
\text { Development } \\
\text { Journal of Small Business } \\
\text { Management }\end{array}$ & 2019 \\
$\begin{array}{l}\text { Journal of Technology in } \\
\text { Society } \\
\text { Qualitative Market } \\
\text { Research: An } \\
\text { International Journal }\end{array}$ & 2015 \\
\hline & 2015 \\
\hline
\end{tabular}

\section{Cluster keyword}

Untuk menganalisis cluster keyword digunakan Vosviewer. Berdasarkan peta visualisasi dapat diperhatikan bahwa lingkaran warna merah merupakan keyword utama, warna hijau merupakan keyword kedua, biru muda untuk keyword ketiga, biru tua untuk keyword keempat, kuning untuk keyword kelima dan ungu untuk keyword keenam. Semakin tipis warna garis menjelaskan bahwa kata kunci tersebut belum begitu banyak digunakan sebagai keyword dan apabila secara langsung kita buka pada software akan terlihat hubungan langsung 
diantara keyword. Warna ungu memiliki garis yang paling tipis dan jika dihubungkan dengan UKM (SMEs), maka digital marketing chanel, e-commerce, small business belum begitu banyak yang mengkajinya.

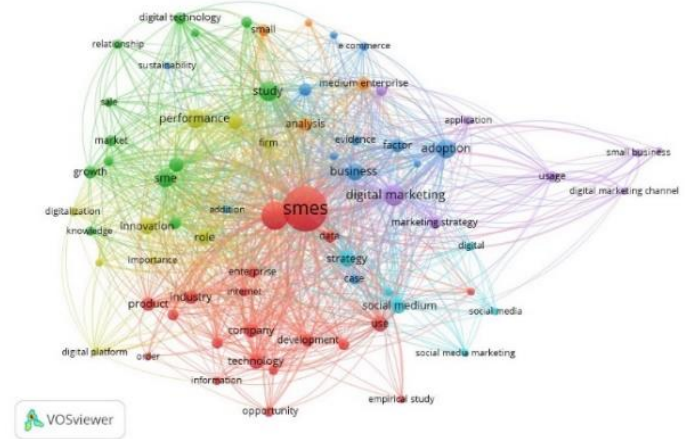

Gambar 5. Peta Visualisasi Jaringan Dari Keyword

Berdasarkan data pada penelitian terdahulu dalam makalah ini baru 1 artikel yang membahas tentang channel tetapi bukan digital marketing channel, sedangkan untuk kata e-commerce pada penelitian terdahulu dalam makalah ini terdapat satu artikel juga yang menggunakannya. Selain garis kita juga perlu memperhatikan besaran titik atau lingkaran, semakin besar bentuk lingkaran artinya semakin banyak keyword itu digunakan demikian sebaliknya semakin kecil lingkaran maka keyword tersebut belum banyak digunakan.Selanjutnya untuk tahun penelitian melalui keyword dapat dilihat pada gambar 6 berikut ini.

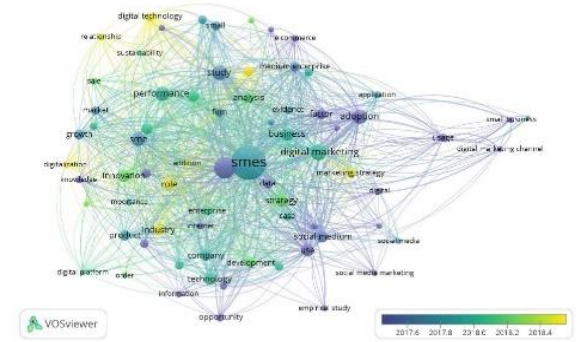

Gambar 6. Peta Visualisasi Jaringan Untuk Tahun Penelitian

Pada gambar 6, dapat dijelaskan bahwa semakin cerah warna dan garis berarti keyword tersebut digunakan pada penelitian yang relatif baru, jika warna kuning artinya penelitian tersebut masih baru diteliti sekitar tahun 2018 bulan April. Untuk keyword digital marketing chanel digunakan sebelum tahun 2017 begitu juga dengan e-commerce karena warnanya yang semakin gelap.

Selanjutnya pada gambar 7 terlihat riset gap dengan jelas bahwa semakin tipis dan pudar tampilan warna maka keyword tersebut semakin jarang digunakan sehingga dapat dijadikan sebagai riset gap pada penelitian bidang digital marketing dan UKM. Keyword tersebut adalah: digital marketing channel, e-commerce, empirical study, digital platform, sustainability dan opportunity. Sehingga ini menjadi peluang bagi peneliti untuk mengkaji lebih dalam.

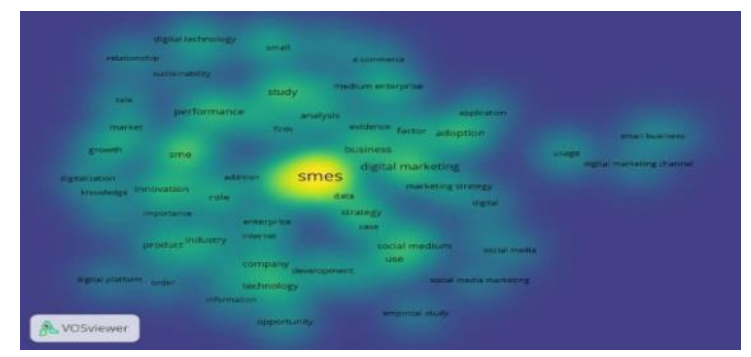

Gambar 7. Peta Visualisasi Jaringan Riset Gap

\section{KESIMPULAN}

Makalah ini merupakan studi literatur terhadap penelitian pada digital marketing dan UKM. Dari 15 artikel yang terpilih setelah dilakukan analisis maka dapat disimpulkan bahwa:

1. Desain penelitian dengan metode survei lebih banyak digunakan.

2. Pada metodologi $53 \%$ artikel menggunakan metode kuantitatif.

3. Pada analisis topik, sebanyak 8 artikel atau $53 \%$ membahas tentang transformasi dan adopsi teknologi digital.

4. Pada taksonomi penelitian dari tahun 2015 -2020 maka artikel yang terbanyak terbit pada International Journal of Information Management dan Journal of Small Business and Enterprise Development.

5. Pada cluster keyword digunakan Vosviewer untuk melakukan pemetaan 
sehingga dapatkan disimpulkan bahwa keyword yang berhubungan digital marketing channel, e-commerce, digital platform, sustainability dan opportunity masih banyak peluang untuk dikaji lebih dalam.

6. Selain keyword untuk penelitian yang akan datang, juga dapat mengembangkan dari sisi metode penelitiannya.

\section{DAFTAR PUSTAKA}

M. Haenlein and A. Kaplan, "A brief history of artificial intelligence: On the past, present, and future of artificial intelligence," Calif. Manage. Rev., vol. 61, no. 4, pp. 514, Aug. 2019, doi: $10.1177 / 0008125619864925$.

L. Bollweg, R. Lackes, M. Siepermann, and P. Weber, "Drivers and barriers of the digitalization of local owner operated retail outlets," J. Small Bus. Entrep., vol. 32, no. 2, pp. 173-201, 2020, doi: 10.1080/08276331.2019.1616256.

Y. S. Chen and S. Y. B. Huang, "The effect of task-technology fit on purchase intention: The moderating role of perceived risks," J. Risk Res., vol. 20, no. 11, pp. 14181438, 2017, doi: 10.1080/13669877.2016.1165281.

S. M. Chege and D. Wang, "The influence of technology innovation on SME performance through environmental sustainability practices in Kenya," Technol. Soc., vol. 60, no. June 2019, p. 101210, 2020, doi: 10.1016/j.techsoc.2019.101210.

H. Bouwman, S. Nikou, and M. de Reuver, "Digitalization, business models, and SMEs: How do business model innovation practices improve performance of digitalizing
SMEs?," Telecomm. Policy, vol. 43, no. 9, 2019, doi: 10.1016/j.telpol.2019.101828.

P. Foroudi, S. Gupta, A. Nazarian, and M. Duda, "Digital technology and marketing management capability: achieving growth in SMEs," Qual. Mark. Res., 2017, doi: 10.1108/QMR-01-2017-0014.

C. Chung and K. P. Austria, "Attitudes Toward Product Messages on Social Media," Int. J. E-Services Mob. Appl., vol. 4, no. 4, pp. 1-14, 2012, doi: 10.4018/jesma.2012100101.

S. Molinillo and A. Japutra, "Organizational adoption of digital information and technology: a theoretical review," Bottom Line, 2017, doi: 10.1108/BL-01-20170002 .

K. U. Mikro, K. Dan, M. Industri, and W. Abdillah, "Kesiapan usaha mikro, kecil dan menengah industri kreatif untuk mengadopsi teknologi informasi," pp. 143-160.

R. Yadav and T. Mahara, "Factors affecting e-commerce adoption by handicraft SMEs of India," $J$. Electron. Commer. Organ., vol. 17, no. 4, pp. 44-57, 2019, doi: 10.4018/JECO.2019100104.

M. A. Camilleri, "The SMEs' technology acceptance of digital media for stakeholder engagement," J. Small Bus. Enterp. Dev., vol. 26, no. 4, pp. 504-521, 2019, doi: 10.1108/JSBED-02-2018-0042.

F. Eggers, I. Hatak, S. Kraus, and T. Niemand, "Technologies That Support Marketing and Market Development in SMEs-Evidence from Social Networks," J. Small Bus. Manag., vol. 55, no. 2, pp. 
270-302, 2017, doi: 10.1111/jsbm.12313.

S. Fernandes, A. Belo, and G. Castela, "Social network enterprise behaviors and patterns in SMEs: Lessons from a Portuguese local community centered around the tourism industry," Technol. Soc., vol. 44, pp. 15-22, 2016, doi: 10.1016/j.techsoc.2015.11.004.

R. Purbasari, "Digital Entrepreneurship in Pandemic Covid 19 Era: The Digital Entrepreneurial Ecosystem Framework," vol. 10, no. 1, pp. 114-135.

J. Cenamor, V. Parida, and J. Wincent, "How entrepreneurial SMEs compete through digital platforms: The roles of digital platform capability, network capability and ambidexterity," J. Bus. Res., vol. 100, no. April, pp. 196-206, 2019, doi: 10.1016/j.jbusres.2019.03.035.

S. Chatterjee and A. Kumar Kar, "Why do small and medium enterprises use social media marketing and what is the impact: Empirical insights from India," Int. J. Inf. Manage., vol. 53, no. December 2019, p. 102103, 2020 , doi: 10.1016/j.ijinfomgt.2020.102103.

P. Foroudi, "Qualitative Market Research : An International Journal Article information :," Qual. Mark. Res. An Int. J., vol. 15, pp. 242-267, 2015.

S. Hosseini, G. Fallon, V. Weerakkody, and U. Sivarajah, "Cloud computing utilization and mitigation of informational and marketing barriers of the SMEs from the emerging markets: Evidence from Iran and Turkey," Int. J. Inf. Manage., vol. 46, no. April 2018, pp. 54-69, 2019, doi: 10.1016/j.ijinfomgt.2018.11.011.

S. Hosseini, G. Fallon, V. Weerakkody, and U. Sivarajah, "Cloud computing utilization and mitigation of informational and marketing barriers of the SMEs from the emerging markets: Evidence from Iran and Turkey," Int. J. Inf. Manage., vol. 46, no. April 2018, pp. 54-69, 2019, doi: 10.1016/j.ijinfomgt.2018.11.011.

D. K. Maduku, M. Mpinganjira, and H. Duh, "Understanding mobile marketing adoption intention by South African SMEs: A multiperspective framework," Int. J. Inf. Manage., vol. 36, no. 5, pp. 711723, 2016, doi: 10.1016/j.ijinfomgt.2016.04.018.

H. M. Taiminen and H. Karjaluoto, "The usage of digital marketing channels in SMEs," J. Small Bus. Enterp. Dev., vol. 22, no. 4, pp. 633-651, 2015, doi: 10.1108/JSBED-05-20130073 .

S. M. Chege, D. Wang, and S. L. Suntu, "Impact of information technology innovation on firm performance in Kenya," Inf. Technol. Dev., vol. 26, no. 2, pp. 316-345, 2020, doi: 10.1080/02681102.2019.1573717.

M. Matarazzo, L. Penco, G. Profumo, and R. Quaglia, "Digital transformation and customer value creation in Made in Italy SMEs: A dynamic capabilities perspective," J. Bus. Res., vol. 123, no. October 2020, pp. 642-656, 2021, doi: 10.1016/j.jbusres.2020.10.033.

M. P. Pradhan, D. Nigam, and C. K. Tiwari, "Digital Marketing \& SMEs: An Identification of Research Gap via Archives of Past Research," Int. J. Appl. Eng. Res., vol. 13, no. 8, pp. 
6089-6097, 2018, [Online].

Available:

http://www.ripublication.com.

H. Virtanen, P. Björk, and E. Sjöström, "Follow for follow: marketing of a start-up company on Instagram," $J$. Small Bus. Enterp. Dev., vol. 24, no. 3, pp. 468-484, 2017, doi: 10.1108/JSBED-12-2016-0202.

Y. Y. Lee, M. Falahat, and B. K. Sia, "Drivers of digital adoption: a multiple case analysis among low and high-tech industries in Malaysia," Asia-Pacific J. Bus. Adm., vol. 13, no. 1, pp. 80-97, 2021, doi: 10.1108/APJBA-05-20190093. 